\title{
Reliability of prehospital diagnosis of acute cerebrovascular accident
}

\author{
Michał Karliński ${ }^{1}$, Dorota Kozera-Strzelińska ${ }^{1}$, Halina Sienkiewicz-Jarosz ${ }^{2}$, \\ Iwona Kurkowska-Jastrzębska ${ }^{1}$, Anna Członkowska ${ }^{1}$ \\ ${ }^{1} 2^{\text {nd }}$ Department of Neurology, Institute of Psychiatry and Neurology, Warsaw, Poland \\ ${ }^{2} 1^{\text {st }}$ Department of Neurology, Institute of Psychiatry and Neurology, Warsaw, Poland
}

\begin{abstract}
Introduction. Early and correct suspicion of an acute cerebrovascular accident (CVA) is necessary to minimise the time to reperfusion treatment. Our aim was to evaluate the reliability of a prehospital diagnosis of stroke or transient ischaemic attack made by healthcare professionals referring patients directly to a neurological Emergency Department (ED).

Material and methods. This retrospective analysis included all consecutive patients referred between 1 January and 31 December 2014 by ambulance physicians, paramedics or outpatient physicians to the neurological ED providing care for the 300-350,000 inhabitants of a highly urbanised area. We calculated sensitivity and positive predictive value (PPV) with $95 \%$ confidence intervals $(95 \% \mathrm{Cl})$ for each group of healthcare professionals, and compared the proportions of undetected CVAs.

Results. Of 802 patients referred with a prehospital diagnosis of CVA, 544 were confirmed. Additional 95 CVA cases were referred with a diagnosis other than CVA. The highest sensitivity for detection of any CVA was among ambulance physicians (96\%; 95\% Cl 92-98\%), followed by paramedics (85\%; 95\% Cl 80-90\%; $p<0.001)$ and outpatient physicians (74\%; 95\% Cl 70-79\%; $\mathrm{p}<0.001)$. PPV for stroke was $83 \%(95 \% \mathrm{Cl} 77-87 \%)$ among ambulance physicians, $73 \%(95 \% \mathrm{Cl} 65-80 \%)$ among paramedics, and $56 \%$ (95\% Cl 47-64\%) among outpatient physicians.
\end{abstract}

Conclusions. Ambulance physicians are highly sensitive in diagnosing any CVA, and are correct in 8 out of 10 cases. The inferior performance of paramedics and outpatient physicians indicates the need for regular stroke training for paramedics and the implementation of two-way communication with the stroke team to identify potential candidates for reperfusion therapy before arrival at the ED.

Key words: acute stroke, transient ischaemic attack, emergency medical services, paramedics, misdiagnosis, prehospital diagnosis

(Neurol Neurochir Pol 2022; 56 (1): 89-96)

\section{Introduction}

Acute stroke care is highly oriented on time-sensitive reperfusion therapies. It requires continuous optimisation of treatment logistics to achieve the shortest possible door-toneedle or door-to-groin time [1]. Such an approach exerts additional pressure on the Emergency Department (ED) personnel, especially on the neurologist who qualifies the patients for thrombolysis or thrombectomy $[1,2]$.
Not all patients initially suspected of an acute cerebrovascular accident (CVA) actually suffer from stroke or transient ischaemic attack (TIA). A large proportion of conditions mimicking CVA are non-neurological [2-8]. Studies have shown that stroke mimics may account for even half of all suspected strokes [2-8].

Failure to identify stroke mimics by members of the Emergency Medical Services (EMS) may lead to suboptimal use of specialist stroke services and inappropriate treatment,

Address for correspondence: Michał Karliński, $2^{\text {nd }}$ Department of Neurology, Institute of Psychiatry and Neurology, Sobieskiego 9, 02-957 Warsaw, Poland; e-mail: mkarlinski@ipin.edu.pl

Received: 12.08.2021 Accepted: 5.11.2021 Early publication date: 28.01.2022

This article is available in open access under Creative Common Attribution-Non-Commercial-No Derivatives 4.0 International (CC BY-NC-ND 4.0) license, allowing to download articles and share them with others as long as they credit the authors and the publisher, but without permission to change them in any way or use them commercially. 
including intravenous thrombolysis. On the other hand, missed diagnoses of stroke may result in delayed admission and delayed or denied reperfusion therapy. Both these scenarios can have legal consequences, as in recent years the attention paid to medical errors has clearly increased [2-4].

An incorrect initial diagnosis of stroke or transient ischaemic attack (TIA) can be made in the Emergency Department (ED) or during a hospital stay in a non-neurological ward [9, 10]. However, in terms of the early diagnostic and therapeutic process, the most important is the suspicion of acute CVA raised by healthcare professionals who refer patients to the hospital [2-4]. Therefore, it is vital to know to what extent the ED physician can rely on the prehospital diagnosis of stroke or TIA. Patients with acute and evident focal deficits in developed healthcare systems are unlikely to wait for an appointment with an outpatient clinic [11].

It also seems important to account for specific features of the EMS, especially the involvement of ambulance physicians. In Poland, if the EMS suspects a stroke, the patient is immediately transported to the nearest hospital with a stroke unit [12]. The ambulance may be staffed with either a physician or a paramedic.

The aim of our study was to evaluate the reliability of prehospital diagnosis of stroke or TIA made by healthcare professionals referring patients directly to a neurological ED.

\section{Material and methods}

This is a retrospective analysis of all available paper and electronic medical records of consecutive patients who reported to our neurological ED between 1 January and 31 December 2014. We identified all cases with a prehospital diagnosis of acute CVA (defined as stroke or TIA) and the final diagnosis of CVA. Patients who reported without any formal referral from a healthcare professional were excluded.

Our hospital provides regular neurological and comprehensive stroke care for c.325,000 inhabitants of a highly urbanised area of Poland (i.e. the southern part of Warsaw plus neighbouring towns). The hospital comprises two neurological wards with stroke units, interventional neuroradiology, neurosurgery, and several psychiatric wards. Stroke units are embedded in neurological wards. The ED is staffed 24/7 with either a senior neurologist or a neurologist in training, both of whom are experienced in treating stroke. Patients admitted to the ED are (i) transported directly by ambulance staffed with either a physician or a paramedic; or (ii) report by themselves with a referral letter from a non-ambulance physician (mostly family medicine specialists or internal medicine specialists); or (iii) report by themselves without any formal referral. Brain computed tomography, brain magnetic resonance imaging, computed tomography-angiography, and a wide range of blood tests are easily available at the ED. The need for advanced diagnostics at the ED to exclude an acute neurological condition does not imply subsequent admission to the neurological ward.
Data was extracted using a predefined form that included information about the patient's gender, age, the type of referring entity (i.e. ambulance physicians or paramedics or non-ambulance physicians), prehospital diagnosis (stroke or transient ischaemic attack or syndrome description highly suggestive of CVA), history of prior stroke, history of seizures, diagnostic workup undertaken at the ED (brain imaging, blood test), final diagnosis, and the decision about admission to the hospital or further referral of patients discharged from the ED [8].

This study complies with the Declaration of Helsinki and was approved by the local Ethics Committee.

This paper follows the Strengthening the Reporting of Observational Studies in Epidemiology (STROBE) Statement [13].

\section{Statistical analysis}

Categorical variables are presented as a number of valid observations and proportions calculated with exclusion of unknown values from the denominator.

The distribution of final diagnoses (stroke/TIA/CVA mimic) in each group of referring healthcare professionals were compared using a chi square test. Pairwise comparisons were preceded by the overall test for significance.

Sensitivity and positive predictive value (PPV) with 95\% confidence intervals $(95 \% \mathrm{CI})$ were calculated separately for each group of healthcare professionals. Sensitivity was defined as the percentage of patients referred to neurological ED with a prehospital suspicion of stroke or TIA among those with a final diagnosis of CVA. PPV was defined as the percentage of patients with a final diagnosis of CVA among those who were referred to neurological ED with a prehospital suspicion of stroke or TIA. Considering the usefulness of prehospital diagnosis for urgent screening of modifiable risk factors and implementation of secondary preventive measures, special emphasis was placed on sensitivity for detection of any CVA. Considering implications for fast track reperfusion therapy, the emphasis was placed on PPV for stroke.

$P$ values of $<0.05$ were considered statistically significant. Calculations were carried out using Dell STATISTICA 13.0 software package (Dell, Round Rock, TX, USA).

\section{Results}

During the study period, there were 1,808 emergency neurological admissions, including 690 patients with confirmed CVAs, of whom 639 presented to the ED with formal referrals from healthcare professionals (Fig. 1). The prehospital diagnosis of CVA was correct in 544 of 802 suspected cases $(68 \%)$. In addition, 95 patients with the final diagnosis of CVA were referred to the ED suspected of a condition other than CVA (Fig. 1).

Conditions most frequently incorrectly suspected of CVA included vertigo (14\%), headache (10\%), seizures (7\%), 


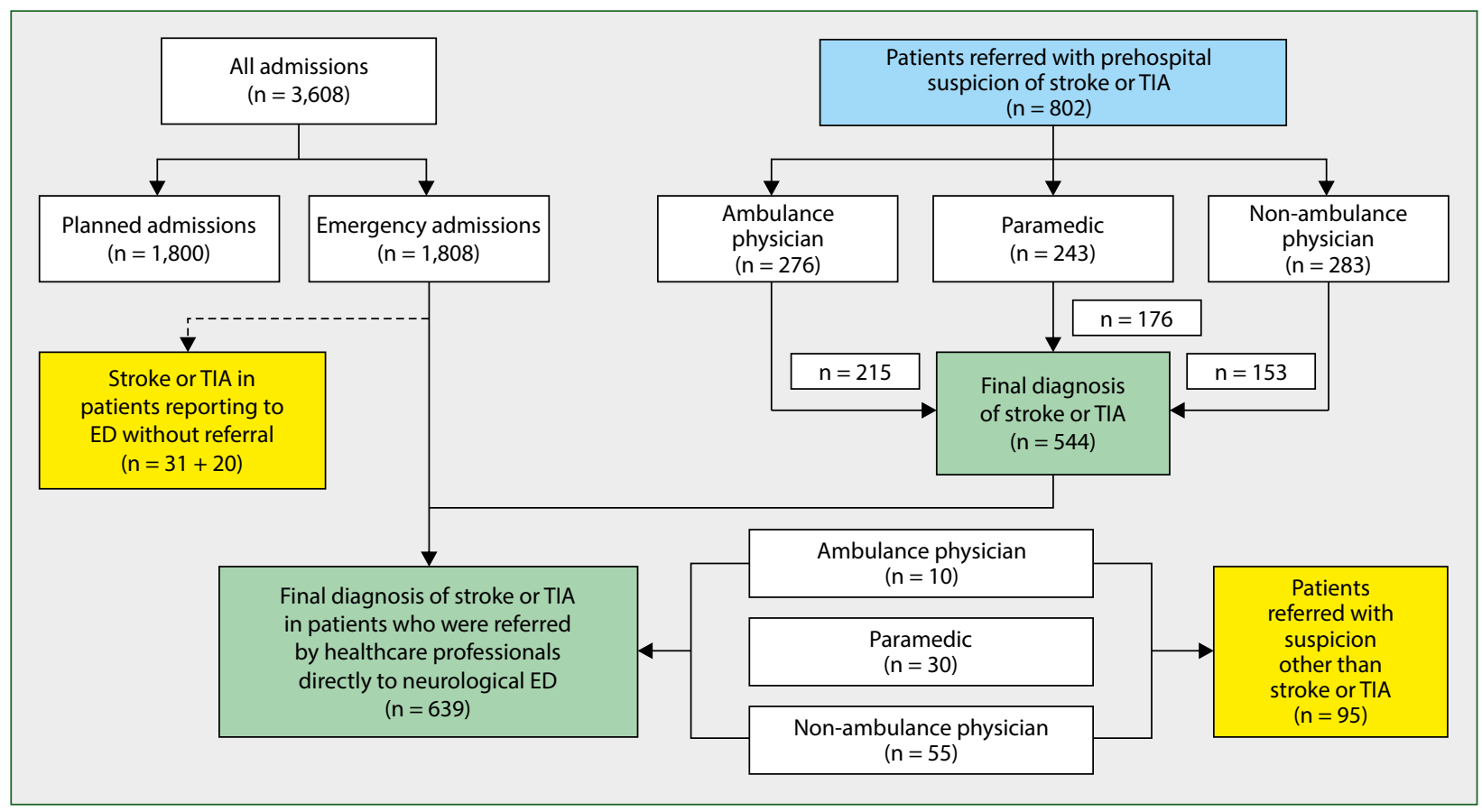

Figure 1. Structure of study population. ED - Emergency Department; TIA - transient ischaemic attack

very high blood pressure (7\%), brain tumour (7\%), sequel of previous cerebral infarction (5\%) and metabolic or electrolyte disturbances 5\%) (Tab. 1).

The distribution of final diagnoses (stroke/TIA/CVA mimic) if any CVA was suspected favoured paramedics over non-ambulance physicians (Tab. 2). In patients suspected particularly of stroke, ambulance physicians performed significantly better than paramedics, and paramedics performed significantly better than non-ambulance physicians (Tab. 2).

Sensitivity and PPV of the prehospital diagnosis of any CVA for the detection of any CVA was $96 \%$ and $78 \%$ for ambulance physicians, $85 \%$ and $72 \%$ for paramedics, whilst only $74 \%$ and $54 \%$ for non-ambulance physicians (Tab. 3 ). Sensitivity and PPV of the prehospital diagnosis of stroke for the detection of any CVA was $95 \%$ and $84 \%, 82 \%$ and $78 \%$, and $65 \%$ and $63 \%$, respectively (Tab. 3). Sensitivity and PPV of the prehospital diagnosis of stroke for the detection of actual stroke was $94 \%$ and $78 \%, 78 \%$ and $60 \%$, and $58 \%$ and $48 \%$ respectively (Tab. 3 ).

\section{Discussion}

The symptoms of stroke can resolve within minutes after the first medical contact, and patients initially labelled as stroke can turn out to have a TIA. It is also possible that minor or fluctuating symptoms will not be detected by ambulance staff and a minor stroke will be labelled as TIA. Therefore it seems reasonable to treat both suspected stroke and suspected TIA as a neurological emergency called CVA [5].
Table 1. Conditions most frequently misdiagnosed as CVA in prehospital setting

\begin{tabular}{lll|} 
& N & $\begin{array}{c}\text { Percentage of all CVA } \\
\text { mimics }(\mathbf{n}=\mathbf{2 5 8})\end{array}$ \\
\hline Vertigo & 36 & $14.0 \%$ \\
Headache & 25 & $9.7 \%$ \\
Seizures & 18 & $7.0 \%$ \\
Very high blood pressure & 18 & $7.0 \%$ \\
Brain tumour & 17 & $6.6 \%$ \\
Sequel of previous cerebral & 14 & $5.4 \%$ \\
infarction & & \\
Metabolic and electrolyte & 14 & $5.4 \%$ \\
disturbances & 13 & $5.0 \%$ \\
Bell's palsy & 12 & $4.7 \%$ \\
Infections & 11 & $4.3 \%$ \\
Syncope & 6 & $2.3 \%$ \\
Cardiac condition & 5 & $1.9 \%$ \\
Alcohol abuse & 48 & $18.6 \%$ \\
Other neurological condition & & $8.1 \%$ \\
Other non-neurological & 21 & \\
condition & & \\
\hline
\end{tabular}

CVA - cerebrovascular accident

This large observational study reports the reliability of a prehospital diagnosis of stroke or TIA made by healthcare professionals acting in prehospital settings. The study gives the unique opportunity to directly compare the performance of ambulance physicians to that of paramedics, these being 
Table 2. Final diagnoses depending on referring entity and type of condition suspected in prehospital setting

\begin{tabular}{|c|c|c|c|c|c|}
\hline & $\begin{array}{c}\text { Ambulance } \\
\text { physicians (1) }\end{array}$ & $\begin{array}{c}\text { Ambulance } \\
\text { paramedics (2) }\end{array}$ & $\begin{array}{c}\text { Non-ambulance } \\
\text { physicians (3) }\end{array}$ & Overall p & $\begin{array}{c}\text { Pairwise } \\
\text { differences }\end{array}$ \\
\hline \multicolumn{6}{|c|}{ Final diagnosis among patients suspected of TIA } \\
\hline Stroke, $\mathrm{n} / \mathrm{N}(\%)$ & $13 / 57(22.8)$ & $17 / 53(32.1)$ & $13 / 99(13.1)$ & 0.040 & $2 v 3$ \\
\hline $\mathrm{TIA}, \mathrm{n} / \mathrm{N}(\%)$ & $19 / 57(33.3)$ & $15 / 53(28.3)$ & $28 / 99(28.3)$ & & \\
\hline CVA mimic, $\mathrm{n} / \mathrm{N}(\%)$ & $24 / 57(42.1)$ & $21 / 53(39.6)$ & $58 / 99(59.6)$ & & \\
\hline \multicolumn{6}{|c|}{ Final diagnosis among patients suspected of stroke } \\
\hline Stroke, $\mathrm{n} / \mathrm{N}(\%)$ & $169 / 216(78.2)$ & $108 / 180(60.0)$ & $76 / 160(47.5)$ & $<0.001$ & $1 \mathrm{v} 2,1 \mathrm{v} 3,2 \mathrm{v} 3$ \\
\hline $\mathrm{TIA}, \mathrm{n} / \mathrm{N}(\%)$ & $12 / 216(5.6)$ & $33 / 180(18.3)$ & $24 / 160(15.0)$ & & \\
\hline CVA mimic, $\mathrm{n} / \mathrm{N}(\%)$ & $35 / 216(16.2)$ & $39 / 180(21.7)$ & $60 / 160(37.5)$ & & \\
\hline \multicolumn{6}{|c|}{ Final diagnosis among patients with syndrome description highly suggestive of CVA } \\
\hline Stroke, n/N (\%) & $1 / 3(33.3)$ & $1 / 10(10.0)$ & $7 / 24(29.2)$ & 0.672 & \\
\hline TIA, n/N (\%) & $0 / 3(0.0)$ & $2 / 10(20.0)$ & $5 / 24(20.8)$ & & \\
\hline CVA mimic, $\mathrm{n} / \mathrm{N}(\%)$ & $2 / 3(66.7)$ & $7 / 10(70.0)$ & $12 / 24(50.0)$ & & \\
\hline
\end{tabular}

CVA - cerebrovascular accident; TIA - transient ischaemic attack

Table 3. Reliability of prehospital diagnosis of stroke or TIA depending on referring entity, with $95 \%$ confidence intervals

\begin{tabular}{|c|c|c|c|}
\hline & Ambulance physicians & Ambulance paramedics & Non-ambulance physicians \\
\hline \multicolumn{4}{|c|}{ Suspected any CVA $\triangle$ confirmed stroke or TIA } \\
\hline Sensitivity & $96 \%(92-98 \%)$ & $85 \%(80-90 \%)$ & $74 \%(68-80 \%)$ \\
\hline PPV & $78 \%(72-82 \%)$ & $72 \%(66-78 \%)$ & $54 \%(49-61 \%)$ \\
\hline \multicolumn{4}{|c|}{ Suspected stroke $\triangle$ confirmed stroke or TIA } \\
\hline Sensitivity & $95 \%(90-97 \%)$ & $82 \%(76-88 \%)$ & $65 \%(56-72 \%)$ \\
\hline PPV & $84 \%(78-88 \%)$ & $78 \%(71-84 \%)$ & $63 \%(54-70 \%)$ \\
\hline \multicolumn{4}{|c|}{ Suspected stroke $\nabla$ confirmed stroke } \\
\hline Sensitivity & $94 \%(90-97 \%)$ & $78 \%(70-85 \%)$ & $58 \%(49-66 \%)$ \\
\hline PPV & $78 \%(72-83 \%)$ & $60 \%(52-67 \%)$ & $48 \%$ (40-56\%) \\
\hline
\end{tabular}

CVA — cerebrovascular accident; PPV — positive predictive value; TIA — transient ischaemic attack

the two major groups responsible for bringing in candidates for reperfusion therapy.

Most modern emergency systems are based on paramedics. They are considered sufficiently sensitive and specific in identifying patients with life threatening conditions, but there is a notable heterogeneity between studies and a wide range of estimates [14]. In the past, all ambulances in Poland used to have a physician on board. The system was reorganized in 2010 and currently consists of (i) specialist ambulances for potentially life-threatening responses staffed with a physician, a paramedic or a specialised nurse and a driver, and (ii) basic ambulances staffed with a paramedic or a specialised nurse and a paramedic driver. Since 2010, the system has been constantly shifting towards a model based mostly on paramedics. In 2020, 343 specialist ambulances and 1,238 basic ambulances operated in the area [15]. However, at the time of the study (2014) a large proportion of ambulances still had a physician on board.

Despite differences between previous studies, it may be assumed that overall PPV for initially suspected stroke approaches $75 \%[3,7]$, and ranges from $13 \%$ to $73 \%$ for TIA [16].
However, if the patient is being referred from a nursing home, the PPV for stroke may be more than two-fold lower [17]

In previous studies, ambulance physicians were reported to detect stroke with PPV of $67 \%$ to $83 \%$ [18]. The performance of ambulance paramedics and ambulance nurses seemed inferior, with PPV of $43 \%$ to $69 \%$ [19-25]. Our study directly confirms that ambulance physicians tend to recognise any CVA better than paramedics, and that they are significantly better at recognising acute stroke.

The observed low performance of non-ambulance physicians (mostly family medicine specialists and internal medicine specialists) appears similar to what has been observed in other countries, and in our catchment area a few years ago $[5,7]$. This gap between EMS teams and non-ambulance physicians probably reflects the inconsistent profile of patients seeking outpatient help. Inappropriate referrals from family physicians consume resources, but they are unlikely to impair the management and outcome of individual patients.

It seems more important to ensure that ambulance paramedics are properly trained, and regularly retrained, in basic 
stroke medicine $[26,27]$. The evidence supports brief online stroke-related educational interventions for paramedics. Unfortunately, providing case-by-case feedback does not seem enough to sustain the intervention's effects for longer than three months $[28,29]$. Initial oversensitivity is actually desired and the EMS team should be particularly cautious before discarding on scene the dispatcher's impression of stroke or TIA $[21,27,30]$. In the optimal scenario, each case initially labelled by the EMS as acute CVA should be teleconsulted with a stroke neurologist to avoid unnecessary activation of code stroke [31]. Good telephone communication between the EMS and the stroke centre does not imply longer on-scene times [32]. This would allow the reallocation of some resources to the subgroup of potential candidates for thrombolysis or thrombectomy [23].

Several clinical scales have been developed to help paramedics or other emergency clinicians recognise acute stroke. None is clearly superior, but considering the amount and consistency of supporting evidence it may be reasonable to prefer the Cincinnati Prehospital Stroke Scale in the prehospital setting, and the Recognition of Stroke in the Emergency Room Scale at the ED $[33,34]$. There are also a few simple clinical scales designed to identify stroke patients with large vessel occlusion. Those patients may potentially benefit from direct transport to a thrombectomy centre, bypassing the nearest stroke-ready hospital at the cost of delaying initiation of thrombolysis. It is probably a matter of time, but current evidence is insufficient to support their widespread implementation $[33,35,36]$

In our study period, none of the non-stroke patients was given alteplase, which illustrates that in our hospital such cases are quite infrequent. However, in some centres the proportion of stroke mimics among patients treated with thrombolysis may exceed $10 \%[3,37,38]$.

\section{Study limitations}

Our study has several limitations. Being a retrospective analysis of consecutive cases, it relies on standard source medical documentation. To maximise the chances of capturing all relevant information, both electronic and paper records were searched. It should be noted that our findings may be biased towards the better performance of prehospital services. In multi-profile hospitals, the proportion of undetected CVA may be higher as well as the tendency to overuse the CVA label to justify delivering a patient with unclear symptoms.

Considering the standard operating procedures of the Polish EMS, we may safely presume that the great majority of patients from our catchment area who were suspected of stroke were actually brought into our ED. It may be that the ambulance dispatchers tended to send out physicians to more severe cases which were more likely to be genuine strokes. However, the suboptimal performance of paramedics was also revealed in previous studies [19-25].

\section{Conclusions}

Sensitivity in diagnosing any CVA in the prehospital setting appears high for ambulance physicians and quite high for ambulance paramedics. The significantly lower sensitivity of non-ambulance physicians is less relevant, as the great majority of patients who report to the hospital in the hyperacute phase of a stroke or TIA call for an ambulance.

The ability to correctly suspect stroke on scene, and therefore deliver a clear candidate for reperfusion therapy, is modest. Prehospital diagnosis of stroke was correct in 8 out of 10 referrals from ambulance physicians but in only 6 out of 10 referrals from paramedics. Our findings indicate the need for additional systematic stroke-oriented training for family physicians and, more importantly, for paramedics. At the same time, widespread implementation of two-way communication between the EMS and stroke neurologists would allow the avoidance of unnecessary triggering of reperfusion fast track procedures at the ED.

Acknowledgments: We wish to acknowledge Grzegorz Rak, $M D$ and Magdalena Wojdacz, MD for their valuable help with data collection.

Conflicts of interest: None.

Funding: Statutory grant from the Institute of Psychiatry and Neurology for stroke research.

\section{References}

1. Powers W, Rabinstein A, Ackerson T, et al. Guidelines for the early management of patients with acute ischemic stroke. Stroke. 2019; 50: e344-e418, doi: 10.1161/STR.0000000000000211, indexed in Pubmed: 31662037.

2. Bakradze E, Liberman AL. Diagnostic error in stroke - reasons and proposed solutions. Curr Atheroscler Rep. 2018; 20(2): 11, doi: 10.1007/s11883-018-0712-3, indexed in Pubmed: 29441421.

3. McClelland G, Rodgers H, Flynn D, et al. The frequency, characteristics and aetiology of stroke mimic presentations: a narrative review. Eur J Emerg Med. 2019; 26(1): 2-8, doi: 10.1097/ MEJ.0000000000000550, indexed in Pubmed: 29727304.

4. Moulin S, Leys D. Stroke mimics and chameleons. Curr Opin Neurol. 2019; 32(1): 54-59, doi: 10.1097/WC0.0000000000000620, indexed in Pubmed: 30239360.

5. Karliński M, Gluszkiewicz M, Członkowska A. The accuracy of prehospital diagnosis of acute cerebrovascular accidents: an observational study. Arch Med Sci. 2015; 11(3): 530-535, doi: 10.5114/ aoms.2015.52355, indexed in Pubmed: 26170845.

6. Hextrum S, Biller J. Clinical distinction of cerebral ischemia and triaging of patients in the emergency department: mimics, wake-ups, late strokes, and chameleons. Neuroimaging Clin N Am. 2018; 28(4): 537-549, doi: 10.1016/j.nic.2018.06.001, indexed in Pubmed: 30322591.

7. Gibson LM, Whiteley W. The differential diagnosis of suspected stroke: a systematic review. J R Coll Physicians Edinb. 2013; 43(2): 114-118, doi: 10.4997/JRCPE.2013.205, indexed in Pubmed: 23734351. 
8. Kozera-Strzelińska D, Karliński M, Rak G, et al. Stroke and TIA mimics in patients referred to a neurological emergency department by non-ambulance physicians, ambulance physicians and paramedics. Neurol Neurochir Pol. 2019; 53(1): 83-89, doi: 10.5603/PJNNS. a2019.0002, indexed in Pubmed: 30614515.

9. Tarnutzer AA, Lee SH, Robinson KA, et al. ED misdiagnosis of cerebrovascular events in the era of modern neuroimaging: A meta-analysis. Neurology. 2017; 88(15): 1468-1477, doi: 10.1212/ WNL.0000000000003814, indexed in Pubmed: 28356464.

10. Topiwala K, Tarasaria $\mathrm{K}$, Staff I, et al. Identifying gaps and missed opportunities for intravenous thrombolytic treatment of inpatient stroke. Front Neurol. 2020; 11: 134, doi: 10.3389/fneur.2020.00134, indexed in Pubmed: 32161567.

11. Lahr MMH, Vroomen PC, Luijckx GJ, et al. Prehospital factors determining regional variation in thrombolytic therapy in acute ischemic stroke. Int J Stroke. 2014; 9(Suppl A100): 31-35, doi: 10.1111/ ijs.12236, indexed in Pubmed: 24373584.

12. Wiszniewska M, Kobayashi A, Czlonkowska A. Postępowanie w udarze mózgu. Skrót Wytycznych Grupy Ekspertów Sekcji Chorób Naczyniowych Polskiego Towarzystwa Neurologicznego z 2012 roku. Pol Przegl Neurol. 2012; 8(4): 161-175.

13. Elm Ev, Altman D, Egger M, et al. The Strengthening the Reporting of Observational Studies in Epidemiology (STROBE) statement: guidelines for reporting observational studies. Lancet. 2007; 370(9596): 1453-1457, doi: 10.1016/s0140-6736(07)61602-x, indexed in Pubmed: 18064739.

14. Wilson C, Harley C, Steels S. Systematic review and meta-analysis of pre-hospital diagnostic accuracy studies. Emerg Med J. 2018; 35(12): 757-764, doi: 10.1136/emermed-2018-207588, indexed in Pubmed: 30217952.

15. Statistics Poland (formerly Central Statistical Office). [Pomoc doraźna i ratownictwo medyczne w 2020 roku]. Warsaw, 06.05.2021. https:// stat.gov.pl/obszary-tematyczne/zdrowie/zdrowie/pomoc-dorazna-i-ratownictwo-medyczne-w-2020-roku,14,5.html (4.11.2021).

16. Kandiyali R, Lasserson DS, Whiting $P$, et al. Predictive values of referrals for transient ischaemic attack from first-contact health care: a systematic review. Br J Gen Pract. 2017; 67(665): e871-e880, doi: 10.3399/bjgp17X693677, indexed in Pubmed: 29158247.

17. Kneihsl M, Enzinger C, Niederkorn K, et al. Stroke referrals from nursing homes: high rate of mimics and late presentation. Cerebrovasc Dis. 2018; 45(3-4): 109-114, doi: 10.1159/000487813, indexed in Pubmed: 29539602.

18. Schewe JC, Kappler J, Dovermann K, et al. Diagnostic accuracy of physician-staffed emergency medical teams: a retrospective observational cohort study of prehospital versus hospital diagnosis in a 10-year interval. Scand J Trauma Resusc Emerg Med. 2019; 27(1): 36, doi: 10.1186/s13049-019-0617-3, indexed in Pubmed: 30940205.

19. Uchida K, Yoshimura S, Hiyama N, et al. Clinical prediction rules to classify types of stroke at prehospital stage. Stroke. 2018; 49(8): 1820-1827, doi: 10.1161/STROKEAHA.118.021794, indexed in Pubmed: 30002147.

20. Neves Briard J, Zewude RT, Kate MP, et al. Stroke mimics transported by emergency medical services to a comprehensive stroke center: the magnitude of the problem. J Stroke Cerebrovasc Dis. 2018; 27(10): 2738-2745, doi: 10.1016/j.jstrokecerebrovasdis.2018.05.046, indexed in Pubmed: 30056002.

21. Jia J, Band R, Abboud ME, et al. Accuracy of emergency medical services dispatcher and crew diagnosis of stroke in clinical practice.
Front Neurol. 2017; 8: 466, doi: 10.3389/fneur.2017.00466, indexed in Pubmed: 28959230.

22. Hansson PO, Andersson Hagiwara M, Herlitz J, et al. Prehospital assessment of suspected stroke and TIA: an observational study. Acta Neurol Scand. 2019; 140(2): 93-99, doi: 10.1111/ane.13107, indexed in Pubmed: 31009075.

23. Brown CW, Macleod MJ. The positive predictive value of an ambulance prealert for stroke and transient ischaemic attack. Eur J Emerg Med. 2018; 25(6): 411-415, doi: 10.1097/MEJ.0000000000000475, indexed in Pubmed: 28538247.

24. Medoro I, Cone DC. An analysis of EMS and ED detection of stroke. Prehosp Emerg Care. 2017; 21(4): 476-480, doi: 10.1080/10903127.2017.1294222, indexed in Pubmed: 28339314.

25. Abboud ME, Band R, Jia J, et al. Recognition of stroke by EMS is associated with improvement in emergency department quality measures. Prehosp Emerg Care. 2016; 20(6): 729-736, doi: 10.1080/10903127.2016.1182602, indexed in Pubmed: 27246289.

26. Hodell E, Hughes SD, Corry M, et al. Paramedic perspectives on barriers to prehospital acute stroke recognition. Prehosp Emerg Care. 2016; 20(3): 415-424, doi: 10.3109/10903127.2015.1115933, indexed in Pubmed: 26855299.

27. Jones SP, Carter B, Ford GA, et al. ESCORTT group. The identification of acute stroke: an analysis of emergency calls. Int J Stroke. 2013; 8(6): 408-412, doi: 10.1111/j.1747-4949.2011.00749.x, indexed in Pubmed: 22335960.

28. Oostema JA, Chassee T, Baer W, et al. Brief educational intervention improves emergency medical services stroke recognition. Stroke. 2019; 50(5): 1193-1200, doi: 10.1161/STROKEAHA.118.023885, indexed in Pubmed: 30917754.

29. Henry-Morrow TK, Nelson BD, Conahan E, et al. An educational intervention allows for greater prehospital recognition of acute stroke. Am J Emerg Med. 2017; 35(12): 1959-1961, doi: 10.1016/j. ajem.2017.05.036, indexed in Pubmed: 28592375.

30. Oostema JA, Carle T, Talia N, et al. Dispatcher stroke recognition using a stroke screening tool: a systematic review. Cerebrovasc Dis. 2016; 42(5-6): 370-377, doi: 10.1159/000447459, indexed in Pubmed: 27348228.

31. Blomberg $\mathrm{H}$, Lundström $\mathrm{E}$, Toss $\mathrm{H}$, et al. Agreement between ambulance nurses and physicians in assessing stroke patients. Acta Neurol Scand. 2014; 129(1): 49-55, doi: 10.1111/ane.12149, indexed in Pubmed: 23710712.

32. Drenck N, Viereck S, Bækgaard JS, et al. Pre-hospital management of acute stroke patients eligible for thrombolysis - an evaluation of ambulance on-scene time. Scand J Trauma Resusc Emerg Med. 2019; 27(1): 3, doi: 10.1186/s13049-018-0580-4, indexed in Pubmed: 30626404.

33. Kobayashi A, Czlonkowska A, Ford GA, et al. European Academy of Neurology and European Stroke Organization consensus statement and practical guidance for pre-hospital management of stroke. Eur J Neurol. 2018; 25(3): 425-433, doi: 10.1111/ene.13539, indexed in Pubmed: 29218822.

34. Zhelev Z, Walker G, Henschke N, et al. Prehospital stroke scales as screening tools for early identification of stroke and transient ischemic attack. Cochrane Database Syst Rev. 2019; 4(4): CD011427, doi: 10.1002/14651858.CD011427.pub2, indexed in Pubmed: 30964558.

35. Luchowski P, Wojczal J, Prus K, et al. Direct admission vs. secondary transfer for mechanical thrombectomy: long-term clinical outcomes from a single Polish Comprehensive Stroke Centre. Neurol Neurochir 
Pol. 2021; 55(5): 494-498, doi: 10.5603/PJNNS.a2021.0050, indexed in Pubmed: 34346053.

36. Karliński M. To drip or to mothership - the ongoing race for stroke thrombectomy. Neurol Neurochir Pol. 2021; 55(5): 416-417, doi: 10.5603/PJNNS.a2021.0070, indexed in Pubmed: 34637135.

37. Kostulas $\mathrm{N}$, Larsson M, Kall TB, et al. Safety of thrombolysis in stroke mimics: an observational cohort study from an urban tea- ching hospital in Sweden. BMJ Open. 2017; 7(10): e016311, doi: 10.1136/bmjopen-2017-016311, indexed in Pubmed: 29084788.

38. Tsivgoulis G, Zand R, Katsanos A, et al. Safety of intravenous thrombolysis in stroke mimics. Stroke. 2015; 46(5): 1281-1287, doi: 10.1161/strokeaha.115.009012, indexed in Pubmed: 25791717. 